\title{
Nouvelle réglementation de la tarification de la LAA à partir de 2007
}

\section{Profitez maintenant de primes avantageuses}

\section{Suppression du tarif unitaire}

Jusqu'en fin 2006 les assureurs dans le domaine de l'assurance accidents LAA était tenu par un tarif unitaire national. Celui-ci était calculé entre eux sur la base de statistiques de risques et émis en recommandation par I'Association Suisse d'Assurances ASA. La libération du domaine des assurances et la révision de la loi des cartels ont obligé I'ASA de ne plus émettre des recommandations. Cela permet à chaque compagnie d'assurances de fixer individuellement le taux de prime. Malheureusement peu de compagnies d'assurances adaptent leur tarif. Actuellement les offres sont encore basées sur les recommandations de l'année 2006.

\section{Contrat collectif de FMH Insurance Services}

En collaboration avec la compagnie d'assurances CPT nous pouvons vous offrir dans le cadre d'un contrat collectif des taux de primes avantageuses. Profitez en, vous et vos collaboratrices et collaborateurs, de ces excellentes conditions et changez de compagnie d'assurances pour l'assurance accidents obligatoire selon LAA à la prochaine échéance de votre actuelle police et contractez un contrat collectif de FMH Insurance Services. Commandez encore aujourd'hui une offre personnelle pour votre cabinet.

\section{Profitez de notre offre}

Vos besoins sont au centre de nos préoccupations. Notre nom vous garantit le conseil professionnel de nos conseillers qui possèdent une longue expérience dans le domaine des assurances, des produits bancaires et financiers. Grâce à notre indépendance nous pouvons vous offrir les meilleurs produits adaptés à vos besoins.

\section{Talon réponse}

Prénom / Nom

Adresse

NPA / Lieu

Date de naissance

Téléphone privé / cabinet

Atteignable le plus facilement (heure)

Prière de m'envoyer une offre LAA de l'assurance collective de FMH Insurance Services. (Prière de joindre une copie de votre police actuelle)

Je désire un conseil personnalisé. Veuillez me téléphoner.

Je m'intéresse pour:

Caisse-maladie

$3^{\text {e }}$ pilier a

Prévoyance LPP

$\mathrm{O}$
Placement avec garantie

Protection juridique

Responsabilité civile profession.

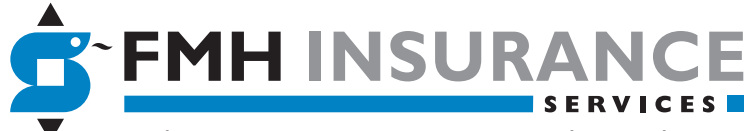

Roth Gygax \& Partner AG $\square$ Service de coordination Moosstrasse 2 - 3073 Gümligen Téléphone 0319595000 - Fax 0319595010 mail@fmhinsurance.ch $\square$ www.fmhinsurance.ch 